San Jose State University

SJSU ScholarWorks

Master's Projects

Master's Theses and Graduate Research

$5-1-2004$

\title{
Maternal-fetal attachment among Vietnamese mothers in the first, second, and third trimesters of pregnancy: A pilot study.
}

Barbara Choo

San Jose State University

Follow this and additional works at: https://scholarworks.sjsu.edu/etd_projects

Part of the Maternal, Child Health and Neonatal Nursing Commons

\section{Recommended Citation}

Choo, Barbara, "Maternal-fetal attachment among Vietnamese mothers in the first, second, and third trimesters of pregnancy: A pilot study." (2004). Master's Projects. 751.

DOI: https://doi.org/10.31979/etd.23v6-6wm3

https://scholarworks.sjsu.edu/etd_projects/751

This Master's Project is brought to you for free and open access by the Master's Theses and Graduate Research at SJSU ScholarWorks. It has been accepted for inclusion in Master's Projects by an authorized administrator of SJSU ScholarWorks. For more information, please contact scholarworks@sjsu.edu. 


\section{SAN JOSE STATE UNIVERSITY SCHOOL OF NURSING}

MASTER'S PROGRAM PROJECT OPTION (PLAN B) PROJECT SIGNATURE FORM

STUDENT NAME Barbara Choo

SEMESTER ENROLLED

TITLE OF PROJECT attachment amone Vietramese women in their first, second, i third trimeoters.

\section{NAME OF JOURNAL}

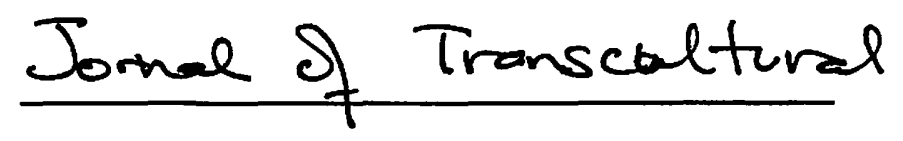

The project and the manuscript have been successfully completed and meet the standards of the School of Nursing University. The project demonstrates the application of professional knowledge, clinical expertise, and scholarly thinking. An abstract of the project and two copies of the manuscript are attached.

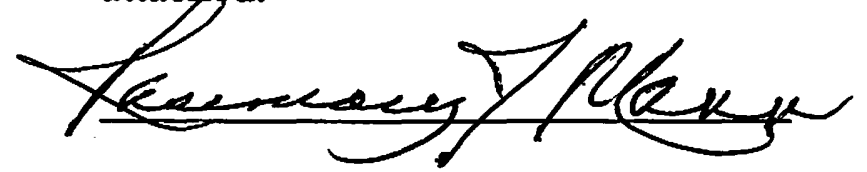

ADVISOR'S SIGNATURE

Qlizibet O.Det

ADVISOR'S SIGNATURE

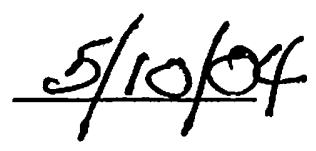

DATE

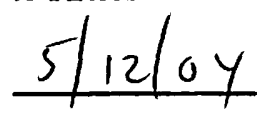

DATE

Please submit the form to the Graduate Coordinator. Attach abstract, two copies of the manuscript, and the documentation of submission to the journal (i.e., postal receipt). 
Maternal-fetal attachment among Vietnamese mothers in the first, second, and third trimesters of pregnancy: A pilot study.

\author{
A Research Proposal \\ Presented to \\ The Faculty of the Division of Health Professions \\ San Jose State University
}

\author{
In Partial Fulfillment \\ of the Requirements for the Degree \\ Master of Science
}

By

Barbara Choo 


\section{Table of Contents}

\section{Page}

Abstract

Introduction

$\begin{array}{ll}\text { Research Questions } & 6\end{array}$

$\begin{array}{ll}\text { Literature Review } & 7\end{array}$

$\begin{array}{ll}\text { Operational Definition } & 7\end{array}$

$\begin{array}{ll}\text { Current Research } & 7\end{array}$

$\begin{array}{ll}\text { Conceptual Framework } & 8\end{array}$

Methodology 11

$\begin{array}{ll}\text { Subject } & 11\end{array}$

$\begin{array}{ll}\text { Instruments } & 12\end{array}$

$\begin{array}{ll}\text { Analysis } & 12\end{array}$

$\begin{array}{ll}\text { Findings } & 13\end{array}$

$\begin{array}{ll}\text { Discussion } & 19\end{array}$

$\begin{array}{ll}\text { Conclusion } & 21\end{array}$

$\begin{array}{ll}\text { References } & 22\end{array}$

Appendix A: Maternal-Fetal Attachment Scale (English) 25

Appendix B: Maternal Fetal Attachment Scale (Vietnamese) 27

Appendix C: Demographic Survey (English) 30

Appendix D: Demographic Survey (Vietnamese) 32

Appendix E: Table 1 33

Appendix F: Table 2 35 
3 MFA

Appendix G: Table 3

Appendix H: Table 4 


\begin{abstract}
Purpose: The purpose of this study was to investigate maternal-fetal attachment (MFA) among Vietnamese women during pregnancy.

Design: This study is a quantitative, descriptive pilot study of maternal fetal attachment among twenty-five Vietnamese women during pregnancy. Convenience sample of twenty-five pregnant Vietnamese women were selected. Two questionnaires were used. The demographic survey included the mother's age, ethnicity, primary language spoken at home, country of origin, parity, and the stage of pregnancy. The Maternal-Fetal Attachment scale (Cranley, 1981) is a twenty-four item self-administered Likert-type scale.
\end{abstract}

Result: The study result's showed modest difference in scores in the three trimesters among the Vietnamese women. There were no apparent differences in maternal and fetal bonding as compared to Cranley's study (1981).

Implications: Findings from this study broadened the health care provider's knowledge regarding cross-cultural nursing in maternal and fetal attachment among Vietnamese women. Larger sample size and revising the language of instruments to accommodate the appropriate cultural background of study subject may yield better results. 
Maternal-Fetal Attachment Among Vietnamese Mothers in the First, Second, and Third Trimesters of Pregnancy: A Pilot Study

Women go through psychological, emotional, physical, and hormonal changes during pregnancy that may affect relationships between mothers and their unborn infants. Rubin (1984) believed the maternal "binding-in" begins even before the birth of the infant. This bond has been called maternal-fetal attachment (MFA). The purpose of this study was to investigate maternal-fetal attachment (MFA) among Vietnamese women during pregnancy.

Gaffney (1988) proposed that inadequate MFA could lead to an "intergenerational" problem as well as being detrimental to an infant's growth and development. In extreme cases, poor MFA may cause child abuse and neglect. In future generations, when infants of abusive parents grow up, the problems continue with social difficulties for attaining and keeping friendships and caring for their own children. Strong MFA may be critical to an infant's future. A mother who experiences less fetal attachment may exhibit destructive behaviors, such as smoking, taking drugs, and not keeping prenatal appointments during pregnancy. Consequently, these behaviors may affect the maternal-fetal attachment and may have an ill effect on the infant's development (e.g. failure to thrive infant).

A distinction between maternal-fetal attachment (MFA) and maternal-infant attachment (MIA) is useful. MFA refers to the process that occurs between the mother and her unborn fetus (Cranley, 1981; Rubin, 1984). MIA refers to the attachment that has developed between the mother and her infant (Bowlby, 1969; Klaus and Kennell, 1976). Maternal-infant deprivation has been associated with "affectionless character" and 
demoralized self-image with subsequent effect on the infant's development and relationships in later life (Bowlby, 1969). "Prolonged deprivation of the young child of maternal care may have grave and far-reaching effects on his character and so on the whole of his future life" (Bowlby, 1969, p.7). Maternal attachment is viewed as a continuum beginning before birth; consequently ways to strengthen and enhance strong MFA before the birth of the infant are critical (Rubin, 1984). Nurses and health care givers need to promote closeness by providing opportunity for mothers to "bind-in" with their fetuses.

Although studies have been conducted on maternal attachment to the fetus and infant, there are limited studies available that evaluate maternal-fetal attachment (MFA) in different cultures. Often there has been selection bias in sampling from previous studies. There are no studies showing how and when maternal attachment is experienced by Vietnamese woman. It may not be appropriate to generalize findings from one culture to mothers from another culture, but it is very possible to make comparisons. In fact, doing so builds our knowledge. Empirical studies are needed to examine whether the findings from previous studies will be applicable to Vietnamese maternal-fetal attachment (MFA). Findings from this study will broaden our knowledge and increase awareness of MFA as experienced by Vietnamese women.

\section{Research Question}

According to Cranley (1981), MFA as measured by maternal role taking, differentiation of self, giving of self, attributing to fetus, and interaction with fetus. The research questions for this study are: 
1. Are maternal-fetal attachment scores different among Vietnamese women as compared to a normative database found in Cranley's study (personal communication, March 14, 2002)?

2. Are maternal-fetal attachment scores different in the three trimesters among the Vietnamese women?

\section{Literature Review}

\section{Operational definition}

According to Merriam-Webster's dictionary, attachment is defined as "the state of being firmly attached to someone or something (as by affection, sympathy, or selfinterest)" (Merriam-Webster Dictionary Online, 2002). Erickson (1996, p. 193) defined maternal-fetal attachment (MFA) "as the process that occurs from the first moment that the mother begins to feel connected to her baby; attachment is the outcome of the bonding process and occurs on a continuum." Rubin (1984) simply explains attachment as a "bind-in" which involves psychological and emotional ties between a fetus and mother during pregnancy.

\section{Current Research}

Many studies have focused on variables affecting pregnancy and attachment. Research topics have included: amniocentesis, infertility, coping, maternal sensitivity, fetal movement, quickening, twin gestations, prenatal depression, health practices, family dynamics, prenatal to postnatal attachment, physical symptoms during pregnancy, paternal relationships with fetus and mother, self-concept, and anxiety. The majority of the studies have focused on maternal-fetal and maternal-infant attachment among white middle-income women (Cranley, 1981; Damato, 2000; Fowles, 1996; Gaffney, 1986; 
Lindgren, 2001; Muller, 1996; Pederson, Gleason, Moran, \& Bento, 1998; Pridham, Lin, \& Brown, 2001; Sorenson \& Schuelke, 1999; Wilson et al., 2000). There is a lack of heterogeneity in the study samples, in terms of cultural diversity, socioeconomic status, education level, and different trimesters of pregnancies.

However, in recent years there were studies among the Japanese (Honjo et al., 2003), Korean (Lee, Cho, Chang, Park, and Lee, 2002), and Swedish mothers (Siddiqui and Hagglof, 2000) in maternal fetal bonding relationships. Honjo et al. (2003) found a strong correlation between maternal-fetal attachment (MFA) and social support in the 216 Japanese women who were in their first and second trimester of pregnancy. However, there were no significant associations between MFA and depression in the early stage of pregnancies. In a Korean study (Lee, Cho, Chang, Park, \& Lee, 2002), 249 pregnant women scored higher in MFA with the visual aid of sonogram pictures of their unborn babies as compared to those mothers who had no visual aid. The researchers also found that, as the pregnancies progressed into the third trimester, the bonding became stronger. Siddiqui and Hagglof (2000) studied 100 pregnant women in their third trimester and at twelve weeks post-partum. Mothers who "fantasized" about their fetuses more during their pregnancies scored higher in the attachment scale and subsequently interacted more often with their newborns.

\section{Conceptual Framework}

Bowlby (1969) proposed that attachment was a strong relationship occurring between an infant and the mother, which was instinctive with a predictable pattern of motherhood nurturing. Researchers have agreed that the deprivation of maternal care and attachment has consequential effects, which will demoralize an infant's self-image and 
subsequently affect future development and relationships (Bowlby, 1969). Some researchers believe attachment occurs immediately after birth (Klaus \& Kennell, 1976), and yet others believe attachment occurs during the gestational period (Cranley, 1981; Rubin, 1984).

Rubin's (1984) theory on attachment was used to define maternal-fetal attachment (MFA). Rubin (1984) believed that attachment formed as maternal identity and maternal tasks were attained during pregnancy. "Binding-in is an affiliative attachment to the child, and this attachment with the formation of maternal identity are interdependent components of the same process" (Rubin, 1984, p. 51). In adulthood, the childbearing experience is part of a "woman's self-system" and can change through time (Rubin, 1984 , p. 26).

Once this role of "feminine identity" has been identified, maternal tasks gradually bind the mother and her fetus psychologically and emotionally. Rubin (1984) proposed four maternal tasks: (a) ensuring safe passage through pregnancy and childbirth (for example, keeping obstetric and prenatal appointments), (b) ensuring acceptance of the child she bears by significant persons in her family (for example, seeking strong social support from spouse or family members), (c) binding-in to her child (for example, becoming aware of her body changes and fetal movement), and (d) learning to give of herself (for example, sharing a box of chocolate).

Fantasy during pregnancy is a form of "binding-in". The mother might fantasize the fetus's physical resemblance either to herself or her husband in regard to eyes or hair color (Sorensen \& Schuelke, 1999). This is a crucial part of a healthy attachment between mother and fetus. During pregnancy, the woman "binds-in" with her fetus by fantasizing 
about her unborn infant. In the first trimester, attachment behavior is observed by the mother's extended conversations with her spouse about the infant's appearance and name (Gaffney, 1988; Rubin, 1984; Sorensen \& Schuelke, 1999). In the second trimester, attachment is observed by the mother's engaging conversations with her fetus in responses to fetal movements (Rubin, 1984). In the third trimester, attachment is observed in the increased maternal emotional investments in the fetus (Gaffney, 1988; Rubin, 1984; Wilson et al., 2000).

According to Rubin (1984), "binding-in" to the fetus depends on the mother's experience and the gestational age of the fetus. During fetal movement, a woman begins to become more aware of the fetus as a living child (Cranley, 1993; Rubin, 1984). Primigravida mothers feel fetal movement around the $20^{\text {th }}$ week of pregnancy and multigravida women feel fetal movement around the $18^{\text {th }}$ week. During the period of "binding-in," a woman experiences an intimate, "narcissistic", and "romantic" love toward her fetus (Rubin, 1984). The attachment is strengthened between a mother and her fetus during this experience.

Rubin (1984) believes that the maternal-fetal attachment "binding-in" continues throughout the gestational period and after birth. If the attachment during pregnancy is not reciprocated as being positive, then there are consequences after birth (Cranley, 1993; Fuller, 1990; Rubin, 1984). There has not been any direct link between maternal-fetal attachment and the development of the fetus. However, studies have shown that the relationship between the mother and her fetus has developmental, psychological, and psychosocial consequences after birth (Bowlby, 1969; Cranley, 1993; Rubin, 1984). Deprivation in developing trust, protection, and security and attaining a relationship with 
others are certainly important to an infant's future development (Bowlby, 1969; Rubin, 1984).

In the late 1970 s and early 1980 s, Cranley began to study the theory of attachment. She developed two instruments known as the Maternal-fetal attachment scale (MFAS) (Cranley, 1981) and Paternal-fetal attachment scale (Weaver \& Cranley, 1983). She believed that attachment began developing during the gestational period. There are certain behavioral characteristics related to maternal-fetal attachment. Cranley (1981, 1993) observed women's behavior during pregnancy as an affiliation and interaction with the fetus. These behaviors included (a) talking to her unborn infant, (b) giving the infant a nickname, and (c) naming the infant.

\section{Methodology}

This study is a quantitative, descriptive pilot study of maternal fetal attachment among Vietnamese women during pregnancy. Two questionnaire surveys were used: a demographic survey and the Maternal-Fetal Attachment scale.

\section{Subjects}

A convenience sample of 25 Vietnamese women was obtained from one Obstetric and Gynecology office in the Northern California area. Women who visited the office were selected for inclusion in this study if they met certain criteria: age between 18-40 years old, Vietnamese background, and low risk pregnancy. Approval was obtained from the San Jose State University (IRB department) to initiate this study. Permission was also obtained from the Obstetric and Gynecology office where data was collected. Once the participants who met the inclusion criteria were selected, a cover letter, informed consent, and instruments were given. The mothers were asked to complete the demographic 
survey and MFA questionnaires during the office visit. Results were tabulated using the Statistical Package for the Social Sciences (SPSS).

\section{Instruments}

The instruments and consent forms were translated into Vietnamese for the convenience of some mothers who preferred the Vietnamese language. Experts in maternal-child nursing who were bilingual at two regional medical centers in Northern California area checked and back translated the surveys for concept equivalence. The demographic survey included the age, ethnicity, primary language spoken at home, country of origin, sex of fetus, parity, and the stage of pregnancy. The MFA scale is a twenty-four item self-administered Likert-type scale. Permission to use the maternal-fetal attachment scale was received from M. Cranley (personal communication, March 14, 2002). Possible responses range from one (definitely no) to 5 (definitely yes). Higher total or mean scores indicate higher levels of maternal-fetal attachment. There are five subscales: differentiation of self from the fetus, interactions with fetus, attributing characteristics and intentions to the fetus, giving of self, and role taking. Convergent validity is supported by a strong correlation $(r=.72)$ of the MFA scale with the Prenatal Attachment Inventory (Cranley, 1981). Cranley (1981) reported that the internal consistency (alpha) was 0.85 . Confidentiality was strictly observed. The MFA scale (Cranley, 1981) and the demographic survey forms were kept anonymous. Analysis

Frequency, mean score, and standard deviation were calculated to determine the scores between the three trimesters. The demographic survey provided statistics on the maternal range of age, educational level, employment status, insurance, and parity. 


\section{Findings}

For this sample of twenty-five Vietnamese women, six were primiparas and nineteen were multiparas (See Table 1). Most women were in their third trimester of pregnancy (sixty-eight percent) while twenty percent were in their second trimester and twelve percent were in their first trimester. Most described their pregnancy as low risk (eighty percent), but twelve percent stated their pregnancy as high risk. In an attempt to gain an indication of perinatal care resources, data on health insurance was collected. Private insurance accounted for thirty-six percent, MediCal for thirty-six percent, and some other means for twenty-eight percent of each woman's payment for care.

Maternal age ranged from eighteen-forty years old with nearly half of the women (forty-eight percent) falling in the range of thirty-one to thirty-five years old. The highest educational degree attainment for thirty-two percent of the women was a high school degree, sixteen percent had a college degree, and four percent had a graduate degree. Thirty-two percent of women attended vocational school or some college while sixteen percent of women did not complete high school. Nearly all women were married and living with their spouse (ninety-two percent), however one woman was unmarried but living with her partner and one woman was unmarried and unpartnered. Forty percent of the women were full time professional employees while twenty percent were unemployed. Thirty-two percent of the women described their occupation as a homemaker while a few were students (eight percent). Three women also maintained part time employment. Most women spoke primarily Vietnamese at home (eighty-eight percent), however English was the primary language for two women and Chinese was the primary language for one woman. 
Table 1

Demographic survey $(\mathrm{N}=25)$

Demographics

Frequency

Percent (\%)

Maternal age

18-20 years old

1

4

21-25 years old

2

8

26-30 years old

8

32

31-35 years old

12

48

$36-40$ years old

2

8

Primiparas

6

24

Multiparas

19

76

First trimester

3

12

Second trimester

5

20

Third trimester

17

68

Pregnancy risk

High risk

3

12

Low risk

22

88

Marital status

Married, living with partner

23

92

Unmarried, living with partner

1

4

Unmarried, unpartner

1

4

Occupation

Professional

10

40 
Homemaker

Student

Unemployed

Insurance

Private

MediCal

Others

Language spoken at home

Vietnamese

English

Chinese

Educational level

Completed high school

Not completed high school

Vocational school

College

Graduate degree
22

2

1
36

36

28

32

8

20

9

7

8

0

2


self from fetus, and giving of self. The mean score for these three subscales ranged from 4.06 to 4.17 (See Table 2), where a "4" corresponded to "Yes" and a " 5 " corresponded to "Definitely yes". In contrast, women were more uncertain, on average, for questions comprising the scales of measuring interaction with fetus and attributing characteristics to the fetus. Mean scores were 3.53 and 3.72, respectively, with a "3" indicating "uncertain" (See Table 2).

Table 2

Total mean score and standard deviation of the maternal-fetal attachment subscales.

\begin{tabular}{lcc}
\hline \multicolumn{1}{c}{ Subscales* } & Mean score* & Standard deviation* \\
\hline Roletaking & 4.17 & 0.57 \\
Differentiation of self & 4.09 & 0.52 \\
Interaction with fetus & 3.53 & 0.55 \\
Attributing characteristics & 3.72 & 0.52 \\
Giving of self & 4.06 & 0.42 \\
\hline
\end{tabular}

${ }^{*} \mathrm{~N}=25$ Vietnamese women

In assessing role-taking, women were especially positive in response to the statements, "I can hardly wait to hold the baby" (ninety-two percent answered yes or definitely yes), "I imagine myself taking care of the baby," (eighty-eight percent answered yes or definitely yes) and "I try to picture what the baby will look like" (eightyeight percent) answered yes or definitely yes). Under the subscale of differentiation of self from fetus, all mothers answered yes or definitely yes to, "I enjoy watching my tummy jiggle as the baby kicks inside," and nearly all agreed that "I really looking forward to seeing what the baby looks like" (ninety-two percent answered yes or 
definitely yes). Regarding the concept of being giving of self, nearly all women felt that all the trouble of being pregnant is worth it, and they eat meat and vegetables to be sure the baby gets a good diet (ninety-six percent answered yes or definitely yes). Less than half of women thought, "my body is ugly" (forty-four percent answered yes or definitely yes).

On the other hand, women's interaction with the fetus and attributing characteristics to the fetus was more subdued. Regarding their interaction with the fetus, most women talked to the unborn baby (eighty-eight percent answered yes or definitely yes) and referred to the baby by a nickname (eighty-four percent answered yes or definitely yes), but less than half stated "I stroke my tummy to quiet the baby when there is too much kicking" (forty-eight percent answered yes or definitely yes) or that "I grasp my baby's foot through my tummy to move it around" (thirty-two percent answered yes or definitely yes). In attributing characteristics to the fetus, many wondered if the baby could hear inside of them (eighty-eight percent answered yes or definitely yes) but fewer women answered positively for the statements, "I can almost guess what my baby's personality will be from the way she/he moves around" and "I can tell that my baby has the hiccoughs" (fifty-two percent answered yes or definitely yes, and thirty-six percent answered yes or definitely yes).

The sentiment of role-taking appeared to drop over time (mean score drops from 4.58 to 4.10 from first to third trimester), yet differentiation from self was highest in the second trimester (4.30) compared to the first (4.00) and third trimester (4.04). In this study, the interaction with the fetus changed little overtime $(3.53,3.48,3.54)$, however attributing characteristics to the fetus was highest in the second and third trimesters (3.80, 
3.75) compared to the first trimester (3.44). Giving of self was highest in the first and third trimesters $(4.07,4.16)$ compared to the second trimester (3.72) (See Table 3).

Table 3

Comparison between the three trimesters's means scores.

\begin{tabular}{lccc}
\hline Subscales & First trimester* & Second trimester** & Third trimester*** \\
\hline Roletaking & 4.58 & 4.15 & 4.10 \\
Differentiation of self from fetus & 4.00 & 4.30 & 4.04 \\
Interaction with fetus & 3.53 & 3.48 & 3.54 \\
Attributing characteristics to fetus & 3.44 & 3.80 & 3.75 \\
Giving of self & 4.07 & 3.72 & 4.16 \\
\end{tabular}

${ }^{*} \mathrm{~N}=3 ;{ }^{* *} \mathrm{~N}=5 ; * * * \mathrm{~N}=17$

Table 4

Comparison data of mean scores between Cranley's study (personal communication, March 14, 2002) and Choo's (2004).

\begin{tabular}{lll}
\hline & Choo* & Cranley** \\
\hline Roletaking & 4.10 & 4.33 \\
Differentiation of self & 4.04 & 4.27 \\
Interaction with fetus & 3.54 & 3.11 \\
Attributing characteristics & 3.75 & 3.22 \\
Giving of self & 4.16 & 4.09 \\
\hline
\end{tabular}

$* \mathrm{~N}=17$ third trimester $* * \mathrm{~N}=326$ third trimester 


\section{Discussion}

There were no apparent differences in this study as compared to Cranley's study (1981) (See Table 4). The sample size was too small for any comparison testing. The Vietnamese women's mean scores were close to Cranley's mean scores (personal communication, March 14, 2002). Both Cranley's (1981) and Choo's (2004) results appear to support the maternal-fetal attachment theory. From this comparison, it could be surmised that Vietnamese mothers appear to nurture their unborn babies by fantasizing, taking care of themselves, and anticipating the birth during pregnancy.

The second research question, MFA scores in three trimesters, was inconclusive. A comparison of subscales across trimesters could not be done with the present data because of the small sample group. There were three women in the first trimester, five women in the second trimester, and seventeen in the third trimester. However some ideas could be proposed. During the first trimester, women (especially the primigravida) may not have experienced fetal movement till twenty weeks of gestation age and multigravida at eighteen weeks of gestation age. Therefore, a mean score of 3.53 in the subscale of interaction with fetus could be related to lack of fetal movement. In the Honjo et al. study (2003), researchers found that the mothers at an early stage of pregnancy did not perceive the reality of the unborn baby. The primigravida mothers were confused about interaction with the unborn child because there were no fetal movements.

It is interesting to note the subscale of interaction with the fetus was the low for both Cranley (third trimester $=3.11$ ) and Choo (first trimester mean score $=3.53$; second trimester mean score $=3.48$; third trimester mean score $=3.54$ ). Perhaps other variables should be investigated. In this modern society, mothers are busy with their careers and 
may not have the time or energy to "fantasize" about their unborn babies. The instruments have not been normed for the Vietnamese culture. For example in the Vietnamese culture, "poking" is not perceived as polite and may have an evil connotation. Social custom in developing a tool needs to be considered. In maintaining healthy pregnancies, these Vietnamese women were "doing certain things" such as eating a good diet and staying healthy in maintaining healthy pregnancies. Yet, $66.7 \%$ of the mothers did not have a name for the baby. Could giving names to the unborn child be bad luck in the Vietnamese culture?

Cultural practices in the Vietnamese culture may have prohibited some of these mothers from doing certain things, like taking Western medicine, to promote the health of the unborn child. Davis (2001) found that Southeast Asian women practiced certain rituals after birth, for example, "appropriate diet" to prevent "varicose veins, headache, and backache". Maternal infant attachment was encouraged through coaching from extended family members: grandmothers, mothers, and aunts among the Southeast Asian and Hmong (Davies 2001; Foss, 2001). Extended family member involvement in caring and coaching the mothers made a difference in how the mothers developed sensitivity with the infant. There is little research investigating cultural practices on maternal and fetal attachment. This study serves to suggest that cultural practices may have an impact on maternal-fetal attachment.

This study was limited by lack of a culturally appropriate instrument. As a pilot study, valuable information has been gleaned about maternal-fetal attachment among Vietnamese women. The instrument should be revised to better accommodate this population. Several questions containing the word "feeling" should be changed. Asian 
women are less expressive and therefore have difficulty understanding what the word means. They interpret "feeling" as a touching gesture, which is inappropriate culturally. The term "high risk pregnancy" also created confusion. Vietnamese women perceived any labor and delivery as high risk. Therefore, careful consideration in wording when developing an instrument for culturally diversified sample is important.

The sample size needs to be increased substantially to include an equal number of women from each trimester. A larger group would permit comparison and correlation in the data analysis. All of these women were selected from one Obstetric and Gynecology office. Additional survey sites from different settings should be considered for a broader picture of Vietnamese women.

\section{Conclusion}

In conclusion, this study has broadened the health care provider's knowledge about maternal-fetal attachment among Vietnamese mothers. In understanding cultural differences, health care providers can provide optimal care in promoting maternal and child health. We need to learn how to work and communicate with women from diverse cultures in order to promote strong bonding relationships with their unborn babies, as well as interaction with the providers. Building a solid foundation for trusting relationships between the mothers and health care providers is essential in strengthening maternal-child health. 


\section{Reference}

Bowlby, J. (1969). Attachment and Loss: Volume I, attachment. London: Hogarth Press.

Cranley, M. (1981). Development of a tool for the measurement of maternal attachment during pregnancy. Nursing Research, 30(5), 281-284.

Damato, E. (2000). Maternal-fetal attachment in twin pregnancies. Journal of Obstetric, Gynecologic, and Neonatal Nursing, 29, 598-605.

Davis, R. (2001). The postpartum experience for Southeast Asian women in the United States. American Journal of Maternal Child Nursing, 26(4), 208-213. Retrieved January 30, 2002, from http://libaccess.sjsu.edu:2125/ovidweb.cgi

Erickson, M. (1996). Predictors of maternal-fetal attachment: An integrative review. The Online Journal of Knowledge Synthesis for Nursing, 3(8).

Foss, G. (2001). Maternal sensitivity, posttraumatic stress, and acculturation in Vietnamese and Hmong mothers. American Journal of Maternal Child Nursing, $26,257-263$.

Fowles, E. (1996). Relationships among prenatal maternal attachment, presence of postnatal depressive symptoms, and maternal role attainment. Journal of the Society of Pediatric Nurses, 1, 75-82.

Gaffney, K. (1986). Maternal-fetal attachment in relation to self-concept and anxiety. Maternal-Child Nursing Journal, 15, 91-101.

Gaffney, K. (1988). Prenatal maternal attachment. Journal of Nursing Scholarship, 20, 106-109.

Honjo, S., Arai, S., Kaneko, H., Ujiie, T., Murase, S., Sechiyama, H., Sasaki, Y., 
Hatagaki, C., Inagaki, E., Usui, M., Miwa, K., Ishihara, M., Hashimoto, O., Nomura, K., Itakura, A., \& Inoko, K. (2003). Antenatal depression and maternalfetal attachment. Psychopathology, 36, 304-311.

Klaus, M., \& Kennell, J. (1976). Maternal-infant bonding. St. Louis: Mosby.

Lee, J., Cho, J., Chang, S., Park, J., \& Lee, Y. (2002). Effect of visual information by ultrasound on maternal-fetal attachment. Journal of the Korean Academy of Women's Health Nursing, 8(3), 335-344.

Lindgren, K. (2001). Relationships among maternal-fetal attachment, prenatal depression, and health practices in pregnancy. Research in Nursing and Health, 24, 203-217. Retrieved January 30, 2002, from http://ibaccess.sjsu.edu:2107/cgi -bin/fulltext?ID=85005877\&PLACEBO=IE.pdf

Merriam-Webster online. (2002). Merriam-Webster's collegiate dictionary. Retrieved March 25, 2002, from http://www.m-w.com/cgi-bin/thesaurus ?book=Thesaurus \&va $=$ attachment

Muller, M. (1993). Development of the prenatal attachment inventory. Western Journal of Nursing Research, 15(2), 199-215.

Muller, M. (1996). Prenatal and postnatal attachment: A modest correlation. Journal of Obstetric, Gynecologic, and Neonatal Nursing, 25, 161-166.

Pederson, D., Gleason, K., Moran, G., \& Bento, S. (1998). Maternal attachment representations, maternal sensitivity, and the infant-mother attachment relationship. Developmental Psychology, 34, 925-933.

Pridham, K., Lin, C., \& Brown, R. (2001). Mothers' evaluation of their care giving for 
premature and full-term infants through the fist year: Contributing factors. Research in Nursing \& Health, 24, 157-169.

Rubin, R. (1984). Maternal identity and the maternal experience. New York: Springer Publishing Company.

Siddiqui, A., \& Hagglof, B. (2000). Does maternal prenatal attachment predict postnatal mother-infant interaction? Early Human Development, 59, 13-25.

Sorensen, D., \& Schuelke, P. (1999). Fantasies of the unborn among pregnant women. The American Journal of Maternal Child Nursing, 24, 92-97.

Weaver, R., \& Cranley, M. (1983). An exploration of paternal-fetal attachment behavior. Nursing Research, 32(2), 68-72.

Wilson, M., White, M., Cobb, B., Curry, R., Greene, D., \& Popovich, D. (2000). Family dynamics, parental-fetal attachment, and infant temperament. [Electronic version]. Journal of Advanced Nursing, 31(1), 204-210. Retrieved March 20, 2002, from http://libaccess.sjsu.edu:2217//ovidweb.cgi. 


\section{Appendix A \\ School of Nursing}

Maternal-fetal attachment among Vietnamese women in their pregnancy

Maternal-Fetal Attachment Scale

Please respond to the following items about yourself and the baby you are expecting. There are no right or wrong answers. Your first impression is usually the best reflection of your feelings. Make sure you mark only one answer per sentence. I think or do the following:

1. I talk to my unborn baby.

2. I feel all the trouble of being pregnant is worth it.

3. I enjoy watching my tummy jiggle as the baby kicks inside.

4. I picture myself feeding the baby.

5. I'm really looking forward to seeing what the baby looks like.

6. I wonder if the baby feels cramped in there.

7. I refer to my baby by a nickname.

8. I imagine myself taking care of the baby.

9. I can almost guess what my baby's personality will be from the way she/he moves around.

10. I have decided on a name for a girl baby.

11. I do things to try to stay healthy that I would not do if I were not pregnant.

12. I wonder if the baby can hear inside of me.

13. I have decided on a name for a boy baby.

14. I wonder if the baby thinks and feels "things" inside of me.

15. I eat meat $\&$ vegetables to be sure my baby gets a good diet.

16. It seems my baby kicks and moves to tell me it's eating time.

17. I poke my baby to get him/her to poke back.

18. I can hardly wait to hold the baby.

19. I try to picture what the baby will look like.

20. I stroke my tummy to quiet the baby when there is too much kicking.

\begin{tabular}{|c|c|c|c|c|}
\hline $\begin{array}{l}\text { Definitely } \\
\text { Yes }\end{array}$ & Yes & Uncertain & $\begin{array}{l}\mathrm{N} \\
\mathrm{o}\end{array}$ & $\begin{array}{l}\text { Definitely } \\
\text { No }\end{array}$ \\
\hline 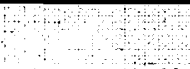 & & & & \\
\hline & & & & \\
\hline & & & & \\
\hline & & & & \\
\hline & & & & \\
\hline & & & & \\
\hline & 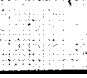 & & & \\
\hline & & & & \\
\hline & & & & \\
\hline & & & & \\
\hline & & & & \\
\hline & & & & \\
\hline & & & & \\
\hline & & & & \\
\hline & & & & \\
\hline & & & & \\
\hline & & & & \\
\hline & & & & \\
\hline & & & & \\
\hline & & & & \\
\hline
\end{tabular}




\section{MFA}

21. I can tell that the baby has hiccoughs.

22. I feel my body is ugly.

23. I give up doing certain things because I want to help my baby.

24. I grasp my baby's foot through my tummy to move it around.

\begin{tabular}{|l|l|l|l|l|}
\hline & & & & \\
\hline & & & & \\
\hline & & & & \\
\hline & & & & \\
\hline
\end{tabular}




\section{Appendix B \\ San Jose State University \\ School of Nursing}

\section{Maternal-fetal attachment among Vietnamese women in their pregnancies}

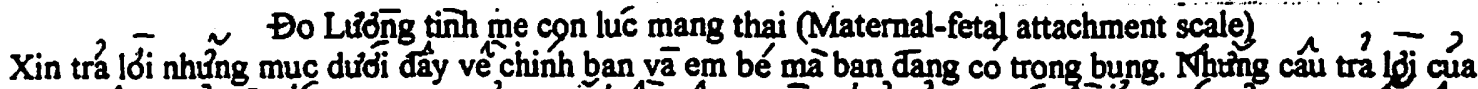

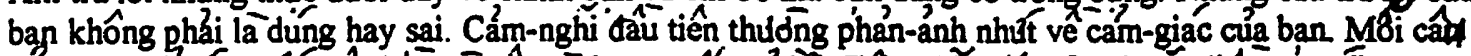

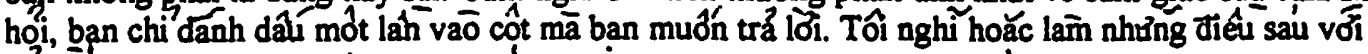
trå lợi nhu sau:

1. Tời nói chuyện với thai-nhi

2. Tôi cåm-nhân tât-cả sự khókhăn dườc màng thai là có giá-tri.

3. Tôi thich-thú sem thai-nhi dang quáy (đap) trong bung tôi.

4. Tói tử'ng-tương tôi cho em bé bú.

5. Tô thष̛̉c sự ước mong dược thấy em bé giâng ai.

6. Tòi thắc-mac nêu em bé bi go-b6 8 trong bung.

7. Tôi thich dăt cho em bé môt cái tên goi thân-mât.

8. Toi tưởng-tường tô đang săn-sóc em bé.

9. Tô hầ phư có thể đóan tính-tinh cua em bé se như thể nāo qua nhưng đồng-tác cua em bé trong bung.

10.Tô đă quyêt-đinh đăt tên cho bé gaí.

11.Yi tôi có thai, tôi ráng lam nhừng gi dêt giti-gin stre-khóe ma thdởng thi tố khồng lam.

12. Tôi thăc-mac nểu em bé trong bung có thế nghe đưởc tôi.

13. Tôi đã quyêt-đinh đặt tên cho be trai.

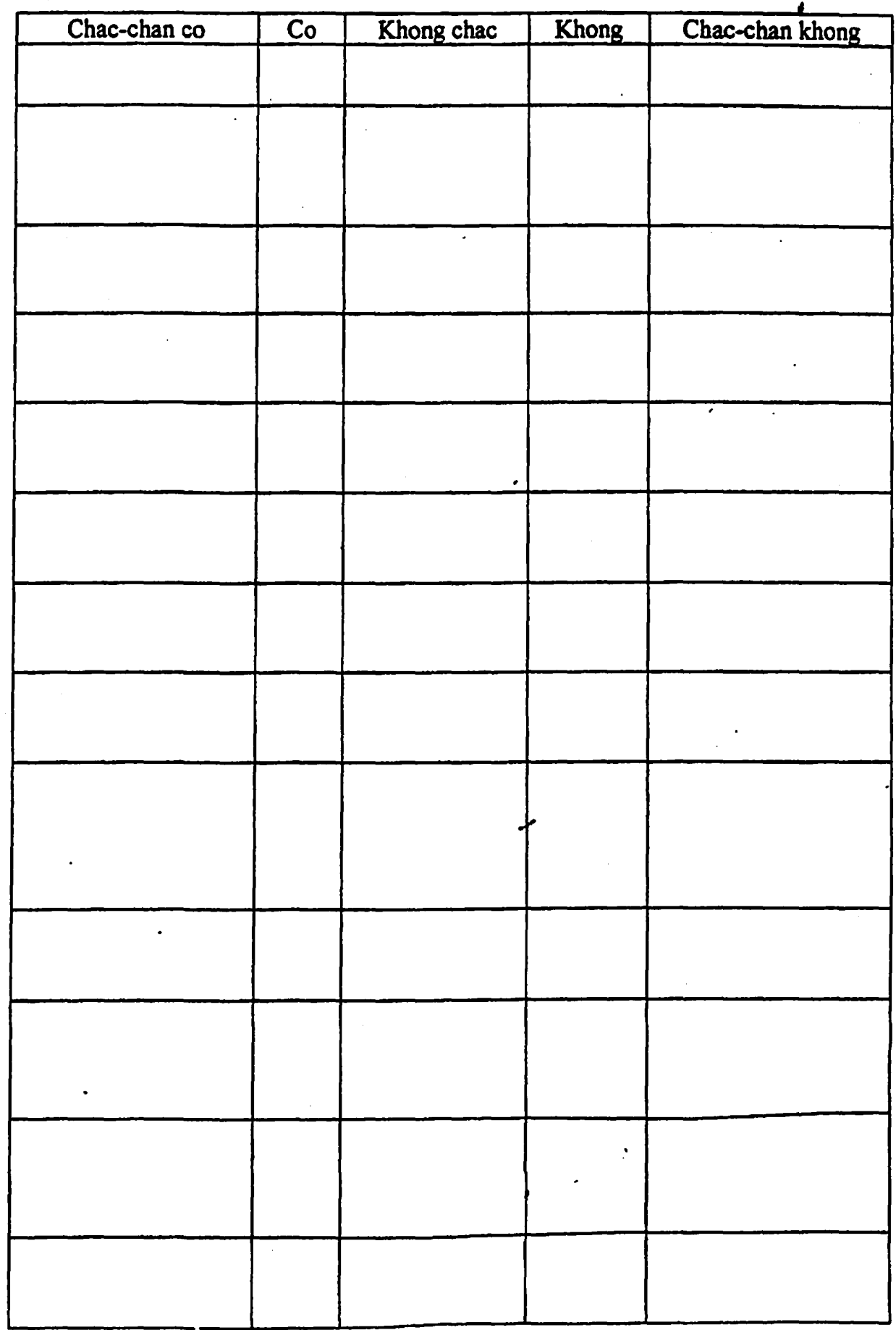


14.Tôi thằ-mắc nể em bé suy-nghi vã câm nhâan sể-viê. 15.Tơ ăn thit và rau dế chăc răng em bé đđược dinh dường tat.

16.Em bé đạp vã̀di-đông trong bung có vê nhỉ bao tôi biett tơi gio ă cula bé.

17. Tô i hầ ngón tay ấ vāo bung để em bé ád'thúc lai tố.

18. Tô jât mong têtiơơc bòng/ân con tố.

19. Tồ cô-găng hinh-dung em bé sẽ giơng ai.

20. Khi em bé quây đap quá ? nhiêu tợ Ań nhe vāo bung dé em bé yên lặng.

21. Tôi có thê nó đực rang em bé bi nấ-cilc:

22. Tô càm-thây thân-thê tôi $x$ ă.

23. Toi nging hoan-toan môt số việ vî tố muốn giúp thảnhi.

24. Tôj chup chân em bé và dichuyể dây dó trong bung.

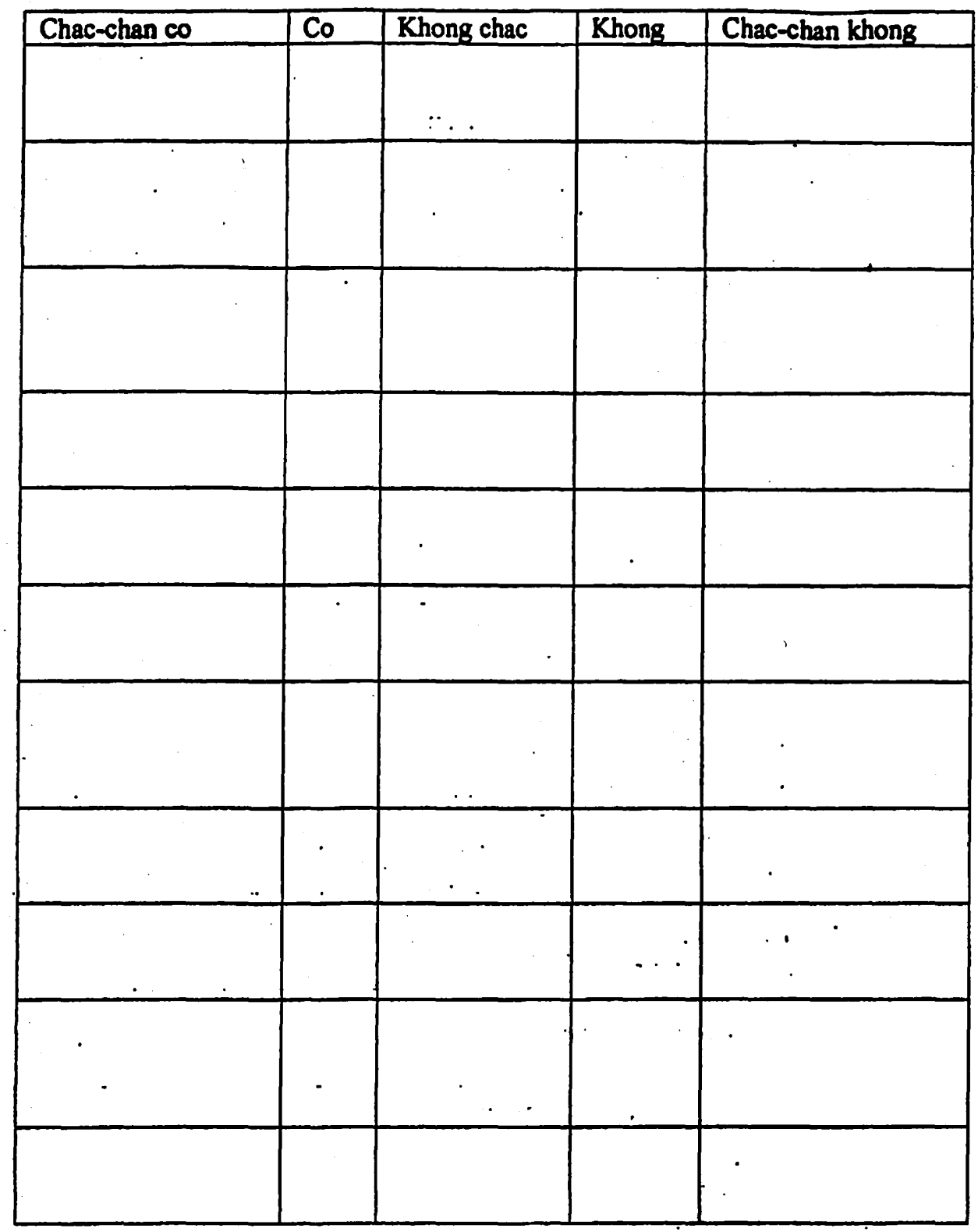




\section{Appendix C}

\section{San Jose State University}

School of Nursing

Maternal-fetal attachment among Vietnamese women in their pregnancies

Demographic Survey

Gestation age: week

Maternal age:

Between 18 and 20

Between 21 and 25

Between 26 and 30

Between 31 and 35

Between 36 and 40

This is my first baby: Yes

No

If answer is no, then this is my baby.

Maternal country of origin:

Language spoken at home:

Maternal highest level of education:

High School: Completed Not Completed

Vocational school/some college:

College:

Graduate degree:

Pregnancy risk:

High risk:

Low risk:

Marital status:

Married, living with partner :

Unmarried, living with partner

Unmarried/unpartnered

Divorced:

Occupation:

Professional

Homemaker

Student

Unemployed

Health insurance: $\quad$ Private Insurance

Medical 
Others

Employment status:

Full-time

Part-time

Unemployed 
Appendix D

Demographic Survey in Vietnamese

\section{Liên Hệ Mật Thiết Giữa Ngưởi Me Và Bà̃ Thai Trong Giới Phụ Nũ Việt Nam Troung Thổi Gian Mang Thai Mấu Diển Cứa Ngửi Tham Gia}

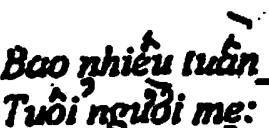

Gipin 18 va 20

Ghis 21 va 25

Gift 26 va 30

Gista 31 va 35

Gर्यिa 36 va 10

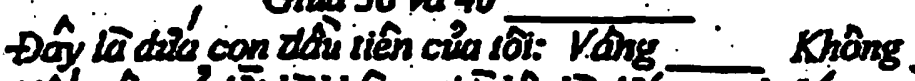

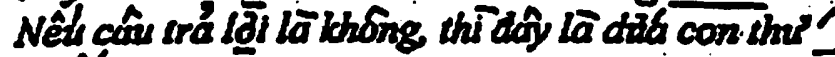

Quñ gia ngulbi me sanh ra.

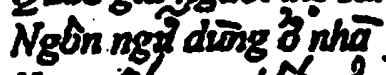

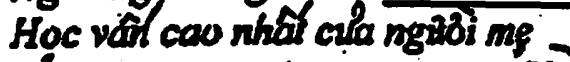

Trung Hoc: Ratriong

Triding mian nght

Van Bang Daj Hoc

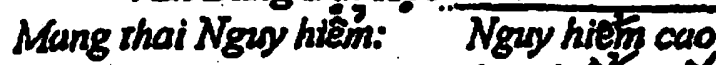

Chita ra eriong

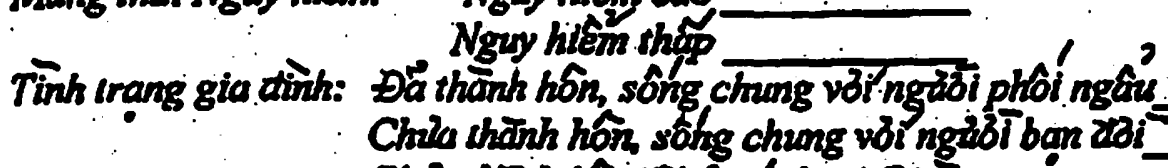

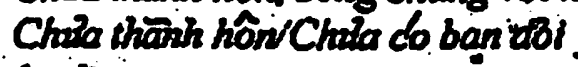

Nghènghiêp: Chryeñ Nghiẹp

Nôi:Tris.

Hoc Sinh

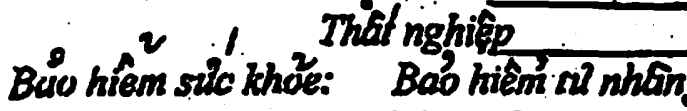

Bedical M Bub hiên khac

Tinh trang nghề nghiẹp: Toann thdi gian

Ban th Dे gicin

Thậ nghiệp. 


\section{Appendix E}

Table 1

Demograhic information of the 25 Vietnamese women

Demographics Frequency

Percent (\%)

Maternal age

18-20 years old

1

4

21-25 years old

2

8

26-30 years old

8

32

31-35 years old

12

48

36-40 years old

2

8

Primiparas

6

24

Multiparas

19

76

First trimester

3

12

Second trimester

5

20

Third trimester

17

68

Pregnancy risk

High risk

3

12

Low risk

22

88

Marital status

Married, living with partner

23

92

Unmarried, living with partner

1

4

Unmarried, unpartner

1

4 


\begin{tabular}{|c|c|c|}
\hline Professional & 10 & 40 \\
\hline Homemaker & 8 & 32 \\
\hline Student & 2 & 8 \\
\hline Unemployed & 5 & 20 \\
\hline \multicolumn{3}{|l|}{ Insurance } \\
\hline Private & 9 & 36 \\
\hline MediCal & 9 & 36 \\
\hline Others & 7 & 28 \\
\hline \multicolumn{3}{|l|}{ Language spoken at home } \\
\hline Vietnamese & 22 & 88 \\
\hline English & 2 & 8 \\
\hline Chinese & 1 & 4 \\
\hline \multicolumn{3}{|l|}{ Educational level } \\
\hline Completed high school & 8 & 32 \\
\hline Not completed high school & 4 & 16 \\
\hline Vocational school & 8 & 32 \\
\hline College & 4 & 16 \\
\hline Graduate degree & 1 & 4 \\
\hline
\end{tabular}




\section{Appendix F}

Table 2

Total mean score and standard deviation of the maternal-fetal attachment subscales.

\begin{tabular}{lcc}
\hline \multicolumn{1}{c}{ Subscales* } & Mean score* & Standard deviation* \\
\hline Roletaking & 4.17 & 0.57 \\
Differentation of self & 4.09 & 0.52 \\
Interaction with fetus & 3.53 & 0.55 \\
Attributing characteristics & 3.72 & 0.52 \\
Giving of self & 4.06 & 0.42 \\
\hline
\end{tabular}

${ }^{*} \mathrm{~N}=25$ Vietnamese women 


\section{Appendix G}

\section{Table 3}

Comparison between the three trimester's mean scores.

\begin{tabular}{lccc}
\hline Subscales & First trimester* & Second trimester** & Third trimester*** \\
\hline Roletaking & 4.58 & 4.15 & 4.10 \\
Differentiation of self from fetus & 4.00 & 4.30 & 4.04 \\
Interaction with fetus & 3.53 & 3.48 & 3.54 \\
Attributing characteristics to fetus & 3.44 & 3.80 & 3.75 \\
Giving of self & 4.07 & 3.72 & 4.16 \\
\hline
\end{tabular}

${ }^{*} \mathrm{~N}=3 ;{ }^{* *} \mathrm{~N}=5 ;{ }^{* * *} \mathrm{~N}=17$ 


\section{Appendix $\mathrm{H}$}

Table 4

Comparision data of mean scores between Cranley's study (personal communication, March 14, 2002) and Choo's (2004).

\begin{tabular}{lll}
\hline & Choo* $^{*}$ & Cranley** \\
\hline Roletaking & 4.10 & 4.33 \\
Differentiation of self & 4.04 & 4.27 \\
Interaction with fetus & 3.54 & 3.11 \\
Attributing characteristics & 3.75 & 3.22 \\
Giving of self & 4.16 & 4.09 \\
\hline
\end{tabular}

${ }^{*} \mathrm{~N}=17$ third trimester ${ }^{* *} \mathrm{~N}=326$ third trimester 